University of South Carolina

Scholar Commons

$1-21-2013$

\title{
Experimental Determination of Electron-Hole Pair Creation Energy in 4H-SiC Epitaxial Layer: An Absolute Calibration Approach
}

\author{
S. K. Chaudhuri \\ K. J. Zavalla \\ K. C. Mandal \\ University of South Carolina - Columbia, mandalk@engr.sc.edu
}

Follow this and additional works at: https://scholarcommons.sc.edu/elct_facpub

Part of the Electrical and Electronics Commons, Engineering Physics Commons, and the Power and Energy Commons

\section{Publication Info}

Published in Applied Physics Letters, Volume 102, Issue 3, 2013, pages 031109-1-031109-4.

(c) Applied Physics Letters 2013, American Institute of Physics

Chaudhuri, S. K., Zavalla, K. J., \& Mandal, K. C. (21 January 2013). Experimental determination of electronhole pair creation energy in $4 \mathrm{H}-\mathrm{SiC}$ epitaxial layer: An absolute calibration approach. Applied Physics Letters, 102(3), \#031109.

http://dx.doi.org/10.1063/1.4776703

http://scitation.aip.org/content/aip/journal/apl/102/3/10.1063/1.4776703

This Article is brought to you by the Electrical Engineering, Department of at Scholar Commons. It has been accepted for inclusion in Faculty Publications by an authorized administrator of Scholar Commons. For more information, please contact digres@mailbox.sc.edu. 


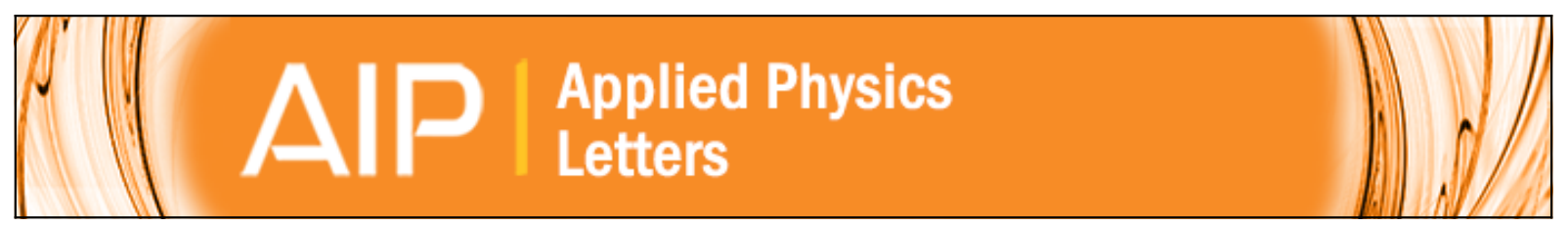

\section{Experimental determination of electron-hole pair creation energy in $4 \mathrm{H}-\mathrm{SiC}$ epitaxial layer: An absolute calibration approach}

Sandeep K. Chaudhuri, Kelvin J. Zavalla, and Krishna C. Mandal

Citation: Applied Physics Letters 102, 031109 (2013); doi: 10.1063/1.4776703

View online: http://dx.doi.org/10.1063/1.4776703

View Table of Contents: http://scitation.aip.org/content/aip/journal/apl/102/3?ver=pdfcov

Published by the AIP Publishing

\section{Articles you may be interested in}

Effect of threading screw and edge dislocations on transport properties of $4 \mathrm{H}-\mathrm{SiC}$ homoepitaxial layers

J. Appl. Phys. 108, 013708 (2010); 10.1063/1.3448230

Average energy dissipated by mega-electron-volt hydrogen and helium ions per electron-hole pair generation in $4 \mathrm{H}-\mathrm{SiC}$

Appl. Phys. Lett. 87, 222105 (2005); 10.1063/1.2135507

Recombination-enhanced defect motion in forward-biased $4 \mathrm{H}-\mathrm{SiC}$ p-n diodes

J. Appl. Phys. 92, 4699 (2002); 10.1063/1.1505994

Amplification of the signal in triode structures of ion detectors based on $6 \mathrm{H}-\mathrm{SIC}$ epitaxial films

Appl. Phys. Lett. 79, 4447 (2001); 10.1063/1.1428765

Structural, electrical, and optical properties of low-doped $4 \mathrm{H}-\mathrm{SiC}$ chemical vapor deposited epitaxial layers J. Appl. Phys. 90, 5402 (2001); 10.1063/1.1406971

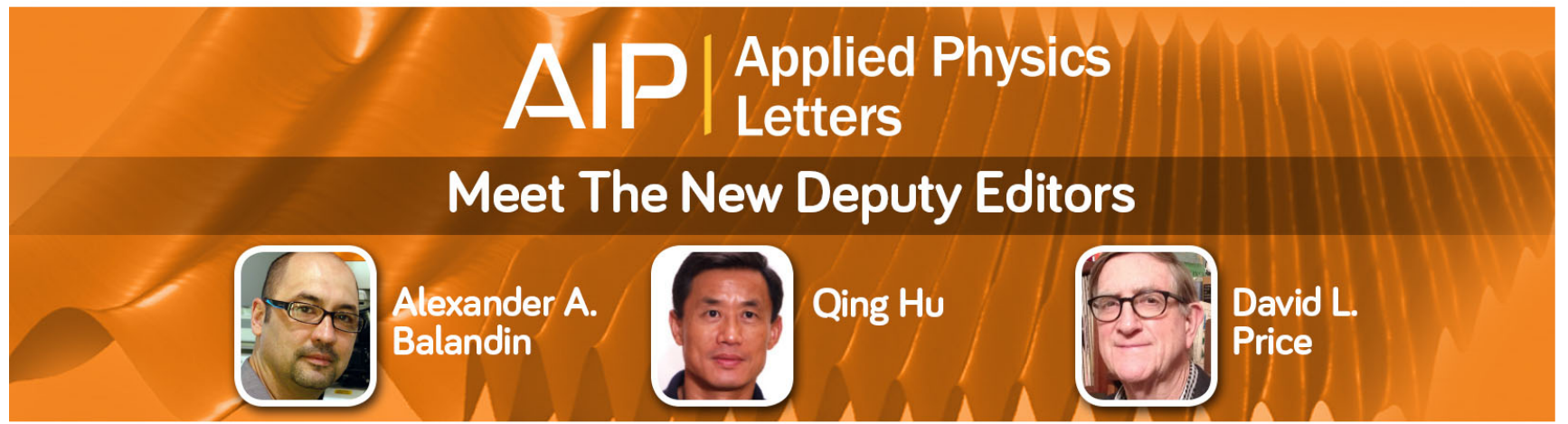




\title{
Experimental determination of electron-hole pair creation energy in $4 \mathrm{H}-\mathrm{SiC}$ epitaxial layer: An absolute calibration approach
}

\author{
Sandeep K. Chaudhuri, Kelvin J. Zavalla, and Krishna C. Mandal ${ }^{\text {a) }}$ \\ Department of Electrical Engineering, University of South Carolina, Columbia, South Carolina 29208, USA
}

(Received 20 November 2012; accepted 2 January 2013; published online 23 January 2013)

\begin{abstract}
Electron-hole pair creation energy $(\varepsilon)$ has been determined from alpha spectroscopy using $4 \mathrm{H}-\mathrm{SiC}$ epitaxial layer Schottky detectors and a pulser calibration technique. We report an experimentally obtained $\varepsilon$ value of $7.28 \mathrm{eV}$ in $4 \mathrm{H}-\mathrm{SiC}$. The obtained $\varepsilon$ value and theoretical models were used to calculate a Fano factor of 0.128 for $5.48 \mathrm{MeV}$ alpha particles. The contributions of different factors to the ultimate alpha peak broadening in pulse-height spectra were determined using the calculated $\varepsilon$ value and Monte-Carlo simulations. The determined $\varepsilon$ value was verified using a drift-diffusion model of variation of charge collection efficiency with applied bias. (C) 2013 American Institute of Physics. [http://dx.doi.org/10.1063/1.4776703]
\end{abstract}

Silicon carbide ( $\mathrm{SiC}$ ), because of its wide band-gap, radiation hardness, and high breakdown field, stands as a very suitable candidate for radiation detectors even in harsh conditions such as high radiation background and hot and humid environments. ${ }^{1-6}$ Among other polytypes, $4 \mathrm{H}-\mathrm{SiC}$ suits best for radiation detection requirements with a band-gap of the order of $3.27 \mathrm{eV},{ }^{7-9}$ smaller anisotropic conductivity ${ }^{10}$ and smaller electron effective mass, or higher mobility. ${ }^{11}$ The desired crystallinity and resistivity for detection purpose are obtained by growing high-resistivity epitaxial layers on $4 \mathrm{H}-\mathrm{SiC}$ substrates.

During a recent alpha spectroscopic measurement with high resolution $4 \mathrm{H}-\mathrm{SiC}$ n-type epitaxial layer detectors, we used a widely accepted value of electron-hole pair creation energy $(\varepsilon)$ of $7.7 \mathrm{eV}$ (Ref. 12) for calibration purpose. We found that this value of $\varepsilon$ overestimated the energy of the $5486 \mathrm{keV}$ alpha particle peak in the pulse-height spectra by several hundred $\mathrm{keV}$. Spectroscopy using semiconductor radiation detectors needs an accurate determination of the energy required to create an electron-hole pair as the ultimate energy resolution depends on the degree of correlation in the number of ionization events. ${ }^{13}$ The accurate determination is generally hindered by the uncertainties involved in the intermediate ionization and energy deposition processes involved prior to the pair creation. It is worth-mentioning here that there exists a considerable amount of disagreement regarding the reported value of $\varepsilon$ in the literature.

$\varepsilon$ values as high as $9 \mathrm{eV}$ for beta rays were reported by Golubev et al. ${ }^{14}$ in $6 \mathrm{H}-\mathrm{SiC}$. An $\varepsilon$ value of $8.4 \mathrm{eV}$ for alpha particles was reported by Rogalla et al. in semi-insulating $4 \mathrm{H}-\mathrm{SiC}{ }^{15}$ Lebedev et al. ${ }^{16}$ have reported $\varepsilon=8.6 \mathrm{eV}$ for alpha particles in epitaxial n-type $4 \mathrm{H}-\mathrm{SiC}$. Slightly lesser values have been reported in epitaxial n-type $4 \mathrm{H}-\mathrm{SiC}$ by Ivanov et al ${ }^{17}, \varepsilon=7.71 \mathrm{eV}$ for alpha particles, and by Bertuccio and Casiraghi, ${ }^{18} \varepsilon=7.8 \mathrm{eV}$ for $59.5 \mathrm{keV}$ gamma rays. A similar value of $7.7 \mathrm{eV}$ for alpha particles was reported by Giudice et al. ${ }^{12}$ in n-type $4 \mathrm{H}-\mathrm{SiC}$. Even $\varepsilon$ value as low as $5.05 \mathrm{eV}$ has been reported by Chandrashekhar et al. ${ }^{19}$ in

\footnotetext{
${ }^{\text {a) }}$ Author to whom correspondence should be addressed. Electronic mail: mandalk@cec.sc.edu.
}

4H-SiC and determined using scanning electron microscopy. The above-mentioned reports involved experiments with either SiC Schottky detectors with window thickness of the order of $100 \mathrm{~nm}$ of high $\mathrm{Z}$ (atomic number) metal or standard silicon detectors for calibration purpose. Thick entrance windows of high $\mathrm{Z}$ metals can lead to considerable amount of uncertainties in the observed incident radiation energy. ${ }^{1}$ On the other hand, calibration with other detectors is a relative calibration process and may ignore other losses in the calibration detectors. These two factors may lead to considerable uncertainties in the determination of $\varepsilon$. Reiterating the remark of Day et al., ${ }^{20}$ it is very important that the study of the ionization process in semiconductors be continued until the theoretical and experimental discrepancies are resolved.

In this letter, we report a method of iterative determination of $\varepsilon$ value which involves an absolute calibration using a precision pulser to match the alpha peak energy $(5486 \mathrm{keV})$ observed using a high resolution 4H-SiC n-type epitaxial Schottky detector. The calculation scheme has been explained in detail in the flowchart in Fig. 1. The absolute calibration was accomplished by injecting pulses of various known amplitudes, $\mathrm{V}_{\text {pulser }}(\mathrm{mV})$, from a precision pulser (Ortec 419) through a calibrated feed-through capacitor, $\mathrm{C}=2.44 \mathrm{pF}$, to the preamplifier input and simultaneously noting down the peak-positions of the shaped pulses in a multi-channel analyzer (MCA). The SiC equivalent of the pulse amplitudes, $\mathrm{E}_{\text {pulser }}$ in $\mathrm{keV}$ was obtained using the following equation:

$$
E_{\text {pulser }}=\frac{V_{\text {pulser }} \times \varepsilon \times C}{q} \text {, }
$$

$\mathrm{q}$ being the electronic charge. The MCA peak positions were then plotted as a function of $\mathrm{E}_{\text {pulser }}$. A linear regression of the data points gave the calibration parameters. The $\varepsilon$ value we obtained using the given procedure was $7.28 \mathrm{eV}$. Figure 2 shows the calibration curve and the related parameters obtained for our detector with the final value of $\varepsilon$ obtained from the iteration cycle.

The detectors used for this study were fabricated on $20 \mu \mathrm{m}$ n-type $4 \mathrm{H}-\mathrm{SiC}$ epilayer grown on a highly doped 


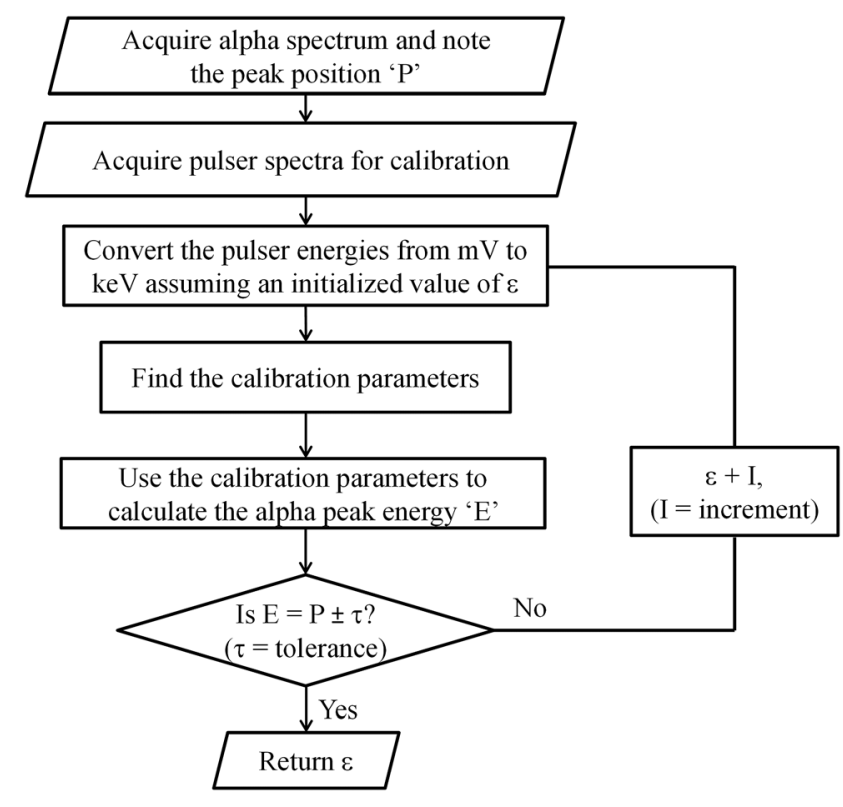

FIG. 1. Flow-chart showing the calculation scheme of electron-hole pair creation energy in $4 \mathrm{H}-\mathrm{SiC}$ n-type epitaxial Schottky detector.

$4 \mathrm{H}-\mathrm{SiC}$ substrate and $4^{\circ}$ off-cut towards the [11-20] direction. The crystal dimensions were $8 \times 8 \mathrm{~mm}^{2}$ which were diced from a $76.2 \mathrm{~mm}$ diameter parent wafer. A micropipe density less than $1 \mathrm{~cm}^{-2}$ was evaluated in the epilayer. The Schottky barrier was accomplished by depositing $\sim 10 \mathrm{~nm}$ thick nickel contacts on the epilayer surface. The effective doping concentration in the epilayer was determined to be $2.4 \times 10^{14} \mathrm{~cm}^{-3}$ from capacitance-voltage measurements. Figure 3 shows the cross-sectional schematic of the detector geometry and a photograph of the detector used in this study mounted on a printed circuit board. Because of the thinner entrance window, the uncertainties (standard deviation) in the $5486 \mathrm{keV}$ incident radiations from a ${ }^{241} \mathrm{Am}$ source were calculated to be only $0.436 \mathrm{keV}$ using a Monte-Carlo simulation code (SRIM 2012). ${ }^{21}$ Another source of uncertainty in the incident energy could be due to the variation of the angle of incidence of the alpha radiations. In our experiment, with a source-detector distance of $12 \mathrm{~mm}$, active source diameter of $7 \mathrm{~mm}$ and a detector window diameter of $\sim 3.8 \mathrm{~mm}$, the deviation in the incident energy was found to be negligible based on SRIM 2012 calculations. Yet another source of uncertainty could arise from the self-absorption in the source. The source calibration data revealed a maximum broadening of $20 \mathrm{keV}$ in the $5486 \mathrm{keV}$ alphas. This uncertainty has been taken into consideration during the calculations by including it as a tolerance.

The determined value of $\varepsilon$ can be used to find other parameters of interest in $\mathrm{SiC}$ by using existing theoretical models of electron-hole pair creation. Klein's phenomenological model ${ }^{13}$ suggests that the average energy required to generate one electron-hole pair is given by the sum of the bandgap $\left(E_{G}\right)$ plus two loss terms viz. phonon-loss $\left(E_{R}\right)$ and thermalization-loss $\left(\mathrm{E}_{\mathrm{K}}\right)$. In his theoretical work, Klein used two dimensionless parameters called the radiation-ionization efficiency $\mathcal{Y}$ and the relative phonon loss $\mathcal{K}$, given by

$$
\mathcal{Y} \equiv E_{G} / \epsilon, \quad \mathcal{K} \equiv E_{R} / E_{G} .
$$
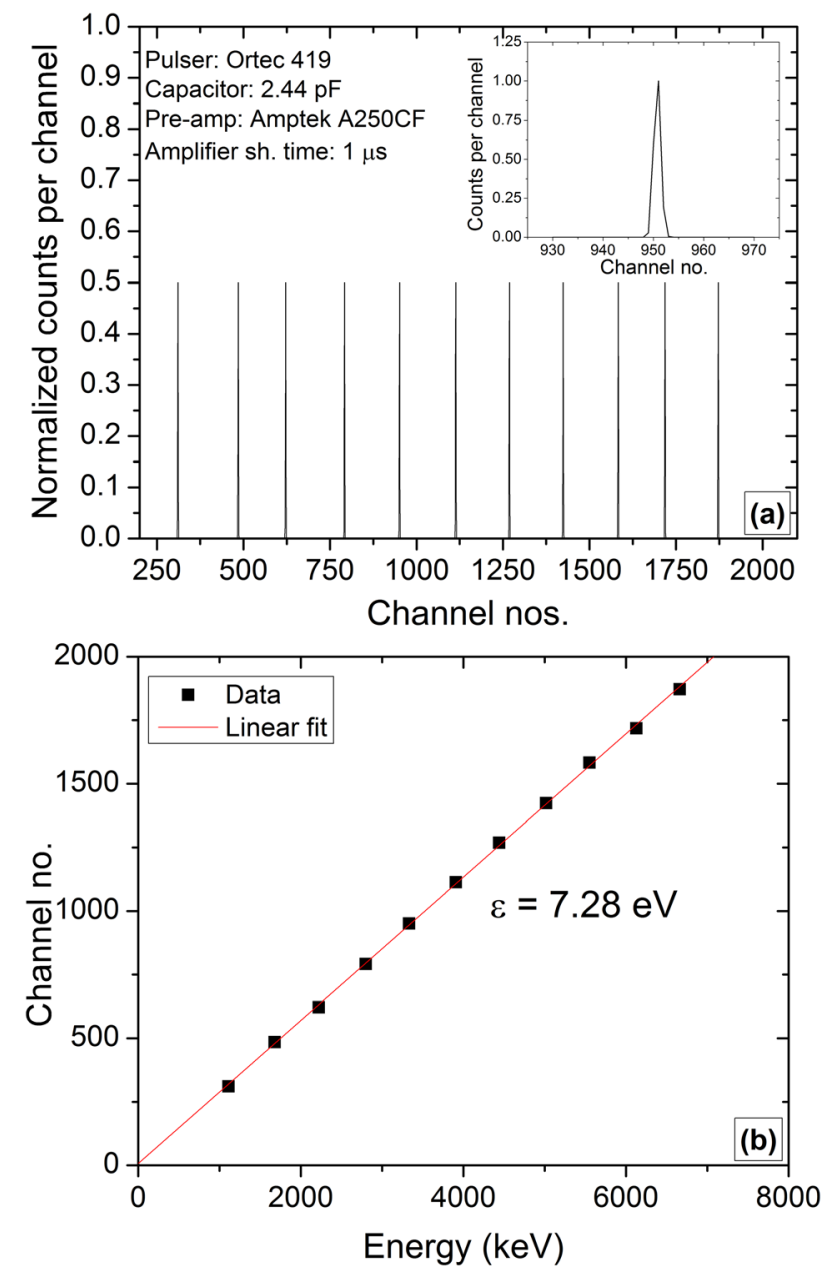

FIG. 2. (a) Pulse height spectra showing variation of pulser peak position as a function of pulser energy. Inset shows a magnified pulser peak. (b) Calibration curve plotted using the $\varepsilon$ value obtained after the final iteration.

Following Shockley's model of electron-hole pair creation energy, ${ }^{22}$ these two quantities can be related as

$$
\mathcal{Y}=(2.80+\mathcal{K})^{-1}
$$

and Klein's formulation in a first approximation leads to the relation between $\mathcal{Y}, \mathcal{K}$, and Fano factor $\mathrm{F}$ given by

$$
F=\left(\mathcal{K}^{2}+0.315\right) \mathcal{Y}^{2} .
$$

Using $\varepsilon=7.28 \mathrm{eV}, \mathrm{E}_{\mathrm{G}}=3.26 \mathrm{eV}$, and Eqs. (2) to (4), we obtained a value of $\mathrm{F}=0.128$ which is higher than the upper limit, $\mathrm{F}=0.04$, estimated by Phlips et al. from $\mathrm{x}$-/gamma ray line width in an ${ }^{241} \mathrm{Am}$ pulse-height spectrum. ${ }^{23}$ There is no other value of Fano factor of $4 \mathrm{H}-\mathrm{SiC}$ detectors reported in the literature. However, Bertuccio and Casiraghi used an F value of 0.12 in one of their works for Fano noise calculations. ${ }^{18}$

The obtained value of $\mathrm{F}$ can be applied to calculate the contribution to the ultimate broadening of peaks in a pulse height spectrum. Figure 4 shows a pulse-height spectrum comprising of $5486 \mathrm{keV}$ alpha-peak and a test pulser peak obtained using our detector. The broadening of a peak $\left(F W H M_{\text {peak }}\right)$ in terms of full width at half maximum (FWHM) in $\mathrm{SiC}$ is given by the quadrature sum of all the contributing broadening factors as shown in the following equation: ${ }^{1,24}$ 

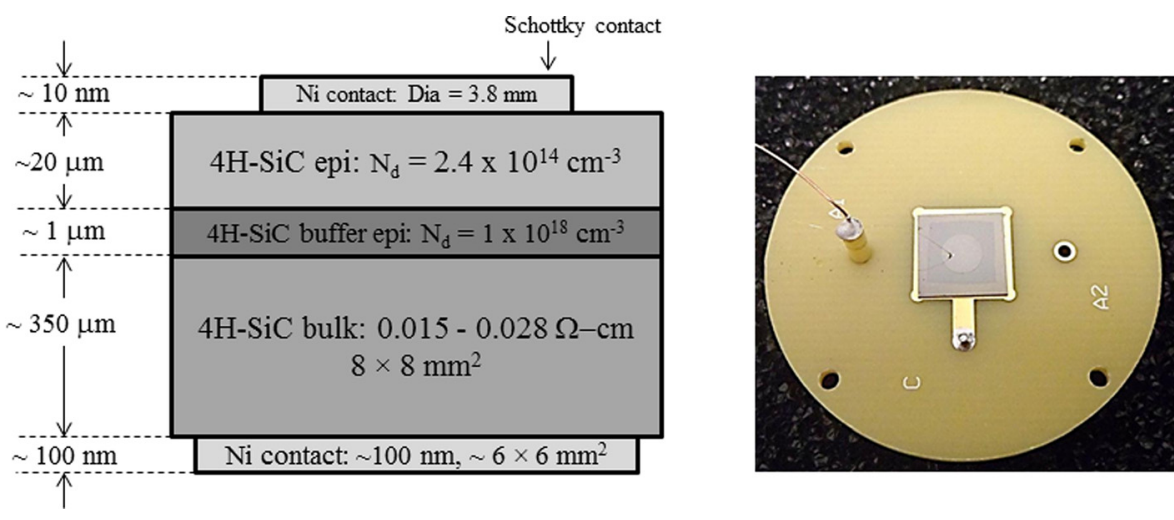

FIG. 3. Cross-sectional schematic of the detector structure used in our studies and a top-view photograph of an actual detector mounted on a printed circuit board.

$$
\begin{aligned}
F W H M_{\text {peak }}^{2}= & F W H M_{\text {elec }}^{2}+F W H M_{\text {leakage }}^{2}+F W H M_{\text {stat }}^{2} \\
& +F W H M_{\text {other }}^{2}+F W H M_{\mathrm{SiC}}^{2}
\end{aligned}
$$

The $F W H M_{\text {peak }}$ was found to be $19.8 \mathrm{keV}$ for the $5486 \mathrm{keV}$ alpha particles. $F W H M_{\text {elec }}$, the broadening due to the noise from the front-end electronics, and $F W H M_{\text {leakage }}$, the broadening due to the detector leakage current, can be collectively obtained from the width of a pulser peak recorded simultaneously with the alpha pulse height spectrum acquisition by injecting a pulser signal to the test input of the pre-amplifier. In the case of our detector, the collective broadening was found to be $15.9 \mathrm{keV}$. FWHM $M_{\text {stat }}$ is the statistical fluctuation in the number of charge carriers produced by an alpha particle which is given by the Fano factor as shown in the following equation:

$$
F W H M_{\text {stat }}=2.355 \sqrt{\varepsilon . F \cdot E_{\text {alpha }}} .
$$

$\mathrm{E}_{\text {alpha }}$ being the incident alpha energy. Using the calculated values of $\varepsilon$ and $\mathrm{F}, F W H M_{\text {stat }}$ was calculated to be $5.3 \mathrm{keV}$. $F W H M_{\text {other }}$ is the broadening due to variation of energy due to the entrance window, the angle of incidence, self-absorption in the source, etc., and was calculated to be 0.436 using Monte Carlo simulations as mentioned before. $F W H M_{\mathrm{SiC}}$ is the

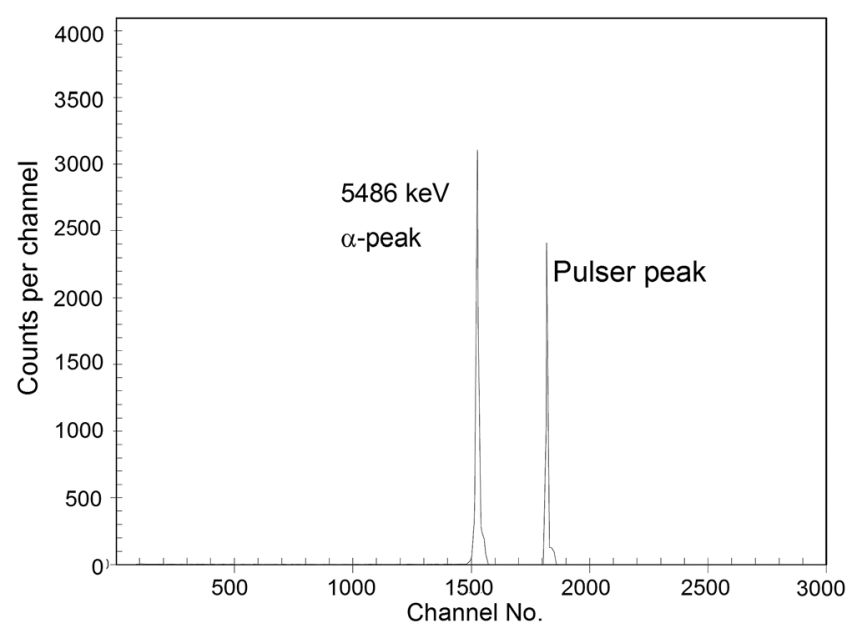

FIG. 4. A pulse-height spectrum obtained using a 4H-SiC n-type epitaxial Schottky detector and a ${ }^{241} \mathrm{Am}$ alpha source. A pulser spectrum was also acquired simultaneously to study the contribution of noise to the ultimate alpha peak width. broadening due to inherent charge collection property of $\mathrm{SiC}$ and using all the above-mentioned FWHM values, $F W H M_{\mathrm{SiC}}$ was found to be $\sim 10.5 \mathrm{keV}$ which is lower compared to the value $(\sim 20 \mathrm{keV})$ reported by Ruddy et al. ${ }^{1}$ probably due to superior charge collection in our $4 \mathrm{H}-\mathrm{SiC}$ epilayer.

The determined $\varepsilon$ value was also put into test by determining the alpha particle induced charge collection efficiency $\left(\mathrm{CCE}_{\mathrm{obs}}\right)$ and comparing those values with a driftdiffusion model of charge collection $\left(\mathrm{CCE}_{\text {theory }}\right){ }^{25}$ Charge collection efficiencies were measured using an alpha source as the ratio of energy deposited in the detector to the actual energy of particles $5486 \mathrm{keV}$ emitted by the source as a function of different bias voltages. According to the driftdiffusion model, $\mathrm{CCE}_{\text {theory }}$ can be represented by the following equation:

$$
\begin{aligned}
C C E_{\text {theory }}= & \frac{1}{E_{\text {alpha }}} \int_{0}^{d}\left(\frac{d E}{d x}\right) d x \\
& +\frac{1}{E_{p}} \int_{d}^{x_{r}}\left[\left(\frac{d E}{d x}\right) \times \exp \left\{-\frac{(x-d)}{L_{d}}\right\}\right] d x \\
= & C C E_{\text {depletion }}+C C E_{\text {diffusion }},
\end{aligned}
$$

where $\mathrm{d}$ is the depletion width at the particular bias, $\mathrm{dE} / \mathrm{dx}$ is the electronic stopping power of the alpha particles calculated using SRIM 2012, $x_{r}$ is the projected range of the alpha particles with energy $E_{p}$, and $L_{d}$ is the diffusion length of the minority carriers. The first term of Eq. (7), $\mathrm{CCE}_{\text {depletion, gives }}$ the contribution to the total CCE of charge generated within the depletion region and the second term, $\mathrm{CCE}_{\text {diffusion, gives }}$ that from the charge carriers created in the region behind the depletion region and diffused to the depletion region. We calculated $\mathrm{CCE}_{\text {depletion }}$ as a function of bias voltage. Figure 5 shows the variation of $\mathrm{CCE}_{\mathrm{obs}}$ and $\mathrm{CCE}_{\text {depletion }}$ as a function of bias voltage. It can be noticed from the figure that $\mathrm{CCE}_{\text {depletion }}$ had a larger deviation from $\mathrm{CCE}_{\text {obs }}$ for bias voltages below $80 \mathrm{~V}$ as the corresponding depletion widths were smaller than or comparable to the alpha penetration depth $(\sim 18 \mu \mathrm{m})$ and hence the contribution of $\mathrm{CCE}_{\text {depletion }}$ to $\mathrm{CCE}_{\text {theory }}$ is partial. For bias voltages above $80 \mathrm{~V}, \mathrm{CCE}_{\text {depletion }}$ values were seen to match $\mathrm{CCE}_{\text {obs }}$ value as the detector was depleted to $\sim 19 \mu \mathrm{m}$ (greater than alpha penetration depth) at and above $80 \mathrm{~V}$ and hence the total contribution to the $\mathrm{CCE}_{\mathrm{obs}}$

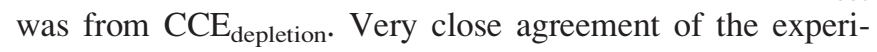
mentally determined values of $\mathrm{CCE}_{\mathrm{obs}}$ with the calculated 


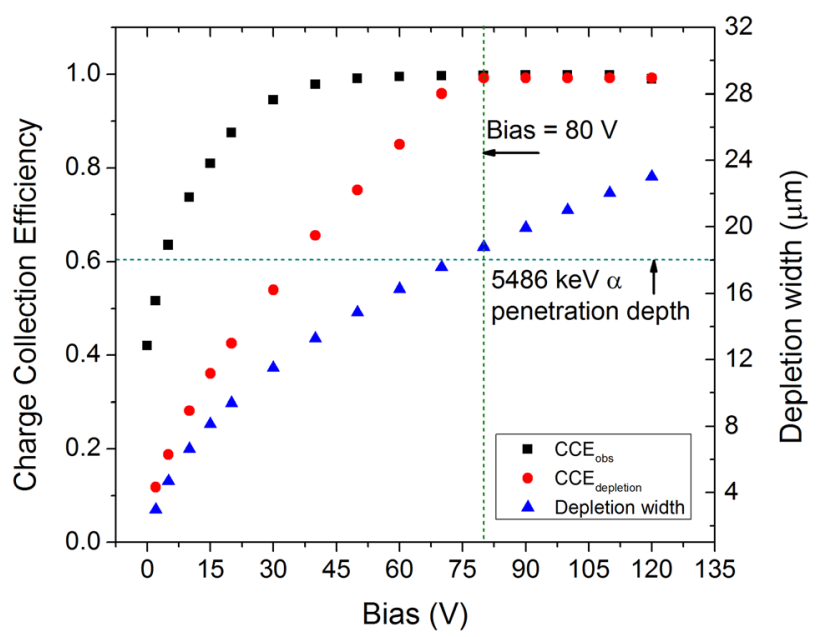

FIG. 5. Variation of experimentally obtained ( $\mathbf{\square})$ charge collection efficiency and theoretically calculated separate contributions to the total CCE from charge drifts in depletion region $(\mathbf{)})$ as a function of bias voltage. The variation of depletion width $(\boldsymbol{\Lambda})$ as a function of bias voltage is also shown in the figure. The vertical dotted line shows the bias at which the depletion width becomes more than the alpha penetration depth and the horizontal one shows the penetration depth for $5486 \mathrm{keV}$ alpha particles.

$\mathrm{CCE}_{\text {depletion }}$ values supports the $\varepsilon$ value obtained from our experiments. As a further test, the experiment was repeated with another detector of similar kind fabricated from a wafer randomly chosen from the $76 \mathrm{~mm}$ parent wafer and the results were found to be perfectly repeatable.

To conclude, we have reported in this letter an experimentally determined electron-hole pair creation energy value of $7.28 \mathrm{eV}$ in order to solve an ambiguity raised during an alpha spectroscopy measurement on using the existing $\varepsilon$ values. We have also calculated a Fano factor value of 0.128 using Klein's formalism which is higher than the previously estimated upper limit of 0.04 in $4 \mathrm{H}-\mathrm{SiC}$. The determined $\varepsilon$ value has been used to calculate the $\mathrm{CCE}$ which matches very well with the CCE values calculated using a driftdiffusion theoretical model of CCE.

One of the authors (K.C.M.) acknowledges partial financial support provided by Los Alamos National Laboratory/ DOE (Grant No. 143479). The authors are thankful to Dr. J. Russell Terry of Los Alamos National Laboratory for C-V measurements.
${ }^{1}$ F. H. Ruddy, J. G. Seidel, H. Chen, A. R. Dulloo, and S.-H. Ryu, IEEE Trans. Nucl. Sci. 53, 1713 (2006).

${ }^{2}$ K. C. Mandal, P. G. Muzykov, and J. R. Terry, Appl. Phys. Lett. 101, 051111 (2012).

${ }^{3}$ K. C. Mandal, P. G. Muzykov, R. M. Krishna, and J. R. Terry, IEEE Trans. Nucl. Sci. 59, 1591 (2012).

${ }^{4}$ G. Bertuccio, R. Casiraghi, A. Cetronio, C. Lanzieri, and F. Nava, Nucl. Instrum. Methods A 522, 413 (2004).

${ }^{5}$ A. Ivanov, E. Kalinina, G. Kholuyanov, N. Strokan, G. Onushkin, A. Konstantinov, A. Hallen, and A. Kuznetsov, in Proceedings of the 5th European Conference on Silicon Carbide and Related Materials 2004, Zurich, Switzerland, edited by R. Nipoti, A. Poggi, and A. Scorzoni (Trans Tech Publications Inc., 2005), p. 1029.

${ }^{6}$ S. K. Chaudhuri, K. J. Zavalla, R. M. Krishna, and K. C. Mandal, Nucl. Instrum. Methods A 701, 214 (2013).

${ }^{7}$ T. Kinoshita, K. M. Itoh, J. Muto, M. Schadt, G. Pensl, and K. Takeda, "Silicon carbide, III nitrides and related materials," Mater. Sci. Forum 264-268, 295 (1998).

${ }^{8}$ W. J. Choyke, H. Matsunami, and G. Pensl, Silicon Carbide-A Review of Fundamental Questions and Applications to Current Device Technology (Springer-Verlag, Berlin, 2004).

${ }^{9}$ G. L. Harris, Properties of SiC, EMIS Data Reviews Vol. 13 (The Institute of Electrical Engineers, London, 1995).

${ }^{10} \mathrm{~B}$. Ellis and T. S. Moss, "The conduction bands in $6 \mathrm{H}$ and $15 \mathrm{R}$ silicon carbide. I. Hall effect and infrared Faraday rotation measurements," Proc. R. Soc. London, Ser. A 299, 383 (1967).

${ }^{11}$ G. A. Lomakina, in Silicon carbide, Proceedings of 3rd International Conference on Silicon Carbide, Miami Beach, Florida (University of South Carolina Press, 1973).

${ }^{12}$ A. Lo Giudice, F. Fizzotti, C. Manfredotti, E. Vittone, and F. Nava, Appl. Phys. Lett. 87, 222105 (2005).

${ }^{13}$ C. A. Klein, J. Appl. Phys. 39, 2029 (1968).

${ }^{14}$ G. P. Golubev, V. S. Vavilov, and V. D. Egorov, Sov. Phys. Solid State 7, 3000 (1966)

${ }^{15}$ M. Rogalla, K. Runge, and A. Soldner-Rembold, Nucl. Phys. B (Proc. Suppl.) 78, 516 (1999).

${ }^{16}$ A. A. Lebedev, A. M. Ivanov, and N. B. Strokan, Semiconductors 38, 125 (2004).

${ }^{17}$ A. M. Ivanov, E. V. Kalinina, A. O. Konstantinov, G. A. Onushkin, N. B. Strokan, G. F. Kholuyanov, and A. Hallén, Tech. Phys. Lett. 30, 575 (2004).

${ }^{18}$ G. Bertuccio and R. Casiraghi, IEEE Trans. Nucl. Sci. 50, 175 (2003).

${ }^{19}$ M. V. S. Chandrashekhar, C. I. Thomas, and M. G. Spencer, Appl. Phys. Lett. 89, 042113 (2006).

${ }^{20}$ R. B. Day, G. Dearnaley, and J. M. Palms, IEEE Trans. Nucl. Sci. 14, 487 (1967).

${ }^{21}$ J. F. Ziegler, J. Biersack, and U. Littmark, The Stopping and Range of Ions in Matter (SRIM) (Pergamon, 1985).

${ }^{22}$ W. Shockley, Solid-State Electron. 2, 35 (1961).

${ }^{23}$ B. F. Phlips, K. D. Hobart, F. J. Kub, R. E. Stahlbush, M. K. Das, B. A. Hull, G. D. Geronimo, and P. O'Conner, in Conference Records: IEEE Nuclear Sciences Symposium 2005, Fajardo, Puerto Rico, October 2005, Paper No. N34-6.

${ }^{24}$ G. F. Knoll, Radiation Detection and Measurement, 3rd ed. (Wiley, New York, 2000), p. 466.

${ }^{25}$ M. B. H. Breese, J. Appl. Phys. 74, 3789 (1993). 